\title{
THE VIEWS OF PARENTS AND ADOLESCENTS ON THE GRANTING OF BEHAVIOURAL AUTONOMY \\ TO ADOLESCENTS: \\ SOME NORMATIVE DATA
}

\author{
ALAN HUDSON \\ Phillip Institute of Technology \\ WENDY BELL \\ Araluen Centre, Lower Plenty \\ TRICIA HUDSON \\ Student Services, \\ Ministry of Education, Victoria \\ VICKI HOUNDOULESI \\ Lincoln Institute of Health Sciences
}

\begin{abstract}
AKNOWLEDGEMENTS: The authors wish to thank the staff of the Ministry of Education Student Services Centre at Camberwell, Coburg, Shepparton and Wodonga for their assistance in the data collection. Segments of the data have been previously reported at the 1984 and 1985 National Conferences of the Australian Behaviour Modification Associations.
\end{abstract}

\begin{abstract}
Psychologists working with families experiencing serious parent adolescent conflict often find themselves being asked about community views regarding the ages at which adolescents ought be permitted to engage in a range of behaviours. Given the general lack of normative data in this regard, the current study has attempted to provide some. Data from two studies involving families of children attending a total of 17 Victorian schools are reported, and discussion is given to the use that might be made of such data by psychologists working with families experiencing parental adolescent conflict.
\end{abstract}

One of the major developmental tasks of adolescence is the gaining of independence from one's parents (Grinder, 1973; Lefrancois, 1976). The process of gaining independence is not always a smooth one, however, and the adolescent period is often punctuated with incidents of conflict among family members. This conflict usually arises from the desire of the adolescent to engage in behaviours such as smoking, drinking, etc., at a younger age than their parents consider to be appropriate.

In the last decade there has been an increasing tendency for psychologists to attempt to ameliorate parent adolescent conflict by teaching family members to negotiate conflict situations (Besalel \& Azrin, 1981; Blechman, 1977; Raue \& Spence, 1985; and Robin, 1980). Such an approach to family intervention usually involves the families focussing on specific issues such as smoking, drinking, etc, and then negotiating a solution which is acceptable to all family members. While it is true that every family is unique and the negotiated solution will be tailored to meet the particular needs of that family, family members are often interested in what other people think about the issues under consideration. The studies reported below were an attempt to gather opinions from parents and adolescents regarding their views about the ages at which adolescents should be granted autonomy to engage in a range of behaviours.

\section{MAJOR STUDY METHOD}

\section{Questionnaire}

A 12 item questionnaire (see Figure 1) was devised by selecting the more frequently occurring issues which formed the basis of parent adolescent conflict for families referred to the Psychology Centre at the Phillip Institute of Technology. The Centre is a psychology clinic which specializes in the treatment of problems of childhood and adolescence.

Completing the questionnaire involved specifying an age at which boys and girls should be able to make decisions for themselves for each item. Additional information sought included the age and sex of the person completing the questionnaire and the age and sex of each child in the person's family.

\section{Sample}

The sample consisted of parents and adolescents from 16 schools in Victoria. In order to examine any socioeconomic difference, seven schools were selected from the north-western suburbs (one secondary and six primary), three were eastern suburbs schools one secondary and two primary) and six were rural schools (two secondary and four primary). The north-western suburbs were considered to be typical blue collar or working class areas, and the eastern suburbs to be typical white collar or middle class areas.

There were 3194 questionnaires distributed to parents 
Figure 1

\section{QUESTIONNAIRE}

In the columns below please indicate at what age you think boys and girls should be allowed to:

\section{Please fill in each box}

\section{BOYS GIRLS}

1. Go shopping to a large complex without their parents

2. Decide when they should leave school

3. Decide what food they eat

4. Decide what time they go to bed

5. Drink alcohol if they want it

6. Decide which television shows they watch

7. Go on dates if they want to

8. Decide what school they will go to

9. Decide which clothes they will wear

10. Decide which films they can go to see

11. Decide time they should come home at night

12. Smoke if they want to

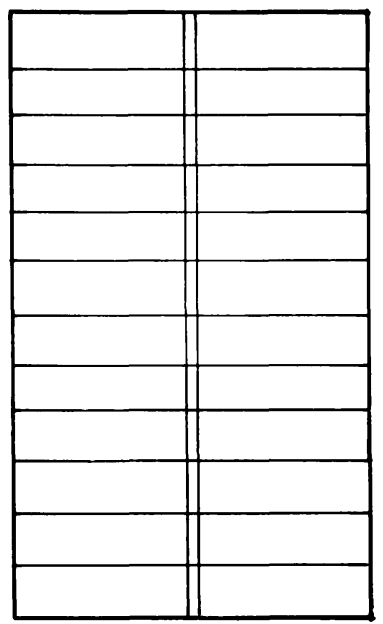

\section{Please also state}

The age of the person completing the questionnaire

The sex (male or female) of the person completing the questionnaire.

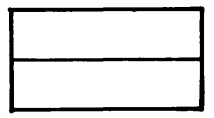

The age and sex of children in your family

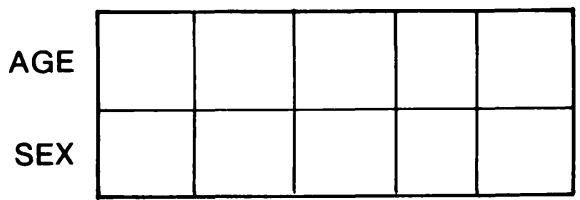


who had children attending these schools. A covering letter was sent home with the questionnaire pointing out the general purpose of the research. In particular it was explained that, while it was appreciated that children matured at different rates, the interest was in their views of the average ages at which adolescents should be permitted to engage in the behaviours in question. A total number of 1584 were returned, of which 1482 were usable. The overall return rate for the parent sample was $39.7 \%$.
The questionnaire was distributed to students in years 7,8 and 9 of the secondary schools in each of the areas. A total of 771 questionnaires was completed by students. As the questionnaires were completed in class, the return rate for adolescents was $100 \%$.

\section{RESULTS}

The means and standard deviations of the responses of parents and adolescents are presented in Table 1 and Table 2 respectively.

Table 1

The Means and Standard Deviations (s.d.) of Responses from Parents by way of Area.

\begin{tabular}{|c|c|c|c|c|c|c|}
\hline \multirow[b]{2}{*}{ Question } & \multicolumn{2}{|c|}{$\begin{array}{c}\text { North-Western } \\
\text { Suburbs } \\
N=568\end{array}$} & \multicolumn{2}{|c|}{$\begin{array}{l}\text { Eastern Suburbs } \\
\qquad N=381\end{array}$} & \multicolumn{2}{|c|}{$\begin{array}{l}\text { Rural area } \\
\mathrm{N} 533\end{array}$} \\
\hline & Mean & s.d. & Mean & s.d. & Mean & s.d. \\
\hline \multicolumn{7}{|l|}{ Boys } \\
\hline 1. Shopping & 13.00 & 2.55 & 12.73 & 1.88 & 12.87 & 1.75 \\
\hline 2. Leave school & 16.42 & 1.56 & 16.04 & 1.04 & 16.04 & 93 \\
\hline 3. Food & 12.19 & 3.59 & 11.87 & 4.13 & 12.23 & 3.65 \\
\hline 4. Bedtime & 14.37 & 2.12 & 13.92 & 2.13 & 14.13 & 1.88 \\
\hline 5. Alcohol & 18.16 & 2.00 & 17.53 & 2.05 & 17.75 & 1.75 \\
\hline 6. T.V. & 13.06 & 3.28 & 12.91 & 3.19 & 13.42 & 2.60 \\
\hline 7. Dates & 16.32 & 1.67 & 15.85 & 1.59 & 15.92 & 1.92 \\
\hline 8. Select school & 13.26 & 2.37 & 14.21 & 2.42 & 13.39 & 2.31 \\
\hline 9. Clothes & 11.75 & 3.02 & 10.88 & 3.58 & 11.35 & 2.99 \\
\hline 10. Films & 14.68 & 2.63 & 14.00 & 2.64 & 14.97 & 2.04 \\
\hline 11. Time home & 17.26 & 1.73 & 17.29 & 1.57 & 17.34 & 1.30 \\
\hline 12. Smoke & 17.61 & 1.56 & 17.70 & 1.73 & 17.47 & 1.67 \\
\hline \multicolumn{7}{|l|}{ Girls } \\
\hline 1. Shopping & 13.34 & 2.72 & 12.72 & 1.88 & 12.89 & 1.75 \\
\hline 2. Leave school & 16.31 & 1.36 & 16.40 & 1.08 & 15.99 & .88 \\
\hline 3. Food & 12.29 & 3.59 & 11.80 & 4.15 & 12.22 & 3.63 \\
\hline 4. Bedtime & 14.36 & 2.16 & 13.87 & 2.13 & 14.07 & 1.94 \\
\hline 5. Alcohol & 18.32 & 2.13 & 17.49 & 2.07 & 17.81 & 1.67 \\
\hline 6. T.V. & 13.07 & 3.35 & 12.87 & 3.22 & 13.38 & 2.59 \\
\hline 7. Dates & 16.47 & 1.69 & 15.77 & 1.61 & 15.93 & 1.05 \\
\hline 8. Select school & 13.26 & 2.42 & 14.12 & 2.38 & 13.33 & 2.29 \\
\hline 9. Clothes & 11.71 & 3.10 & 10.76 & 3.66 & 11.19 & 2.99 \\
\hline 10. Films & 14.87 & 2.57 & 14.00 & 2.69 & 14.98 & 2.05 \\
\hline 11. Time home & 17.81 & 1.18 & 17.42 & 1.65 & 17.43 & 1.30 \\
\hline 12. Smoke & 17.82 & 3.29 & 17.70 & 1.81 & 17.51 & 1.65 \\
\hline
\end{tabular}


Table 2

The Means and Standard Deviations (s.d.) of Responses from Adolescents by way of Area.

\begin{tabular}{|c|c|c|c|c|c|c|}
\hline \multirow[b]{2}{*}{ Question } & \multicolumn{2}{|c|}{$\begin{array}{c}\text { North-Western } \\
\text { Suburbs } \\
\text { N } 270 \\
\end{array}$} & \multicolumn{2}{|c|}{$\begin{array}{c}\text { Eastern Suburbs } \\
\text { N } 262 \\
\end{array}$} & \multicolumn{2}{|c|}{$\begin{array}{c}\text { Rural area } \\
\mathrm{N}=239\end{array}$} \\
\hline & Mean & s.d. & Mean & s.d. & Mean & s.d. \\
\hline $\begin{aligned} \text { Boys } \\
\text { 1. } \\
\text { 2. } \text { Leave school } \\
\text { 3. } \\
\text { 4. Bood } \\
\text { 5. Altime } \\
\text { 6. T.V. } \\
\text { 7. } \\
\text { 8. Sates } \\
\text { 9. } \text { Slothes school } \\
\text { 10. Films } \\
\text { 11. Time home } \\
\text { 12. Smoke }\end{aligned}$ & $\begin{array}{l}12.84 \\
15.77 \\
12.20 \\
13.28 \\
17.19 \\
11.86 \\
14.96 \\
12.76 \\
11.23 \\
13.68 \\
15.66 \\
16.33\end{array}$ & $\begin{array}{l}1.95 \\
0.92 \\
3.28 \\
1.97 \\
1.70 \\
3.20 \\
1.80 \\
1.85 \\
2.72 \\
2.45 \\
1.59 \\
3.78\end{array}$ & $\begin{array}{l}11.61 \\
16.03 \\
11.56 \\
12.76 \\
16.62 \\
11.14 \\
13.59 \\
13.03 \\
10.35 \\
11.86 \\
14.85 \\
15.99\end{array}$ & $\begin{array}{l}1.78 \\
1.23 \\
3.31 \\
2.20 \\
2.47 \\
2.89 \\
2.07 \\
2.20 \\
2.69 \\
2.24 \\
2.00 \\
2.27\end{array}$ & $\begin{array}{l}11.90 \\
15.69 \\
11.68 \\
12.89 \\
16.73 \\
11.33 \\
14.46 \\
12.40 \\
10.28 \\
12.52 \\
14.83 \\
15.62\end{array}$ & $\begin{array}{l}2.31 \\
1.16 \\
3.51 \\
2.36 \\
2.43 \\
3.34 \\
1.99 \\
2.38 \\
2.85 \\
2.63 \\
1.90 \\
2.27\end{array}$ \\
\hline \begin{aligned} & \multicolumn{2}{l}{ Girls } \\
& 1. Shopping \\
& 2. Leave school \\
& 3. Food \\
& 4. Bedtime \\
& 5. Alcohol \\
& 6. T.V. \\
& 7. Dates \\
& 8. Select school \\
& 9. Clothes \\
& 10. Films \\
& 11. Time home \\
& 12. Smoke \end{aligned} & $\begin{array}{l}13.05 \\
15.85 \\
12.26 \\
13.43 \\
17.42 \\
11.90 \\
15.05 \\
12.74 \\
11.21 \\
13.75 \\
15.88 \\
16.72\end{array}$ & $\begin{array}{l}2.02 \\
0.95 \\
3.30 \\
2.28 \\
1.77 \\
3.29 \\
1.19 \\
1.80 \\
2.73 \\
2.48 \\
1.80 \\
4.65\end{array}$ & $\begin{array}{l}11.89 \\
16.15 \\
11.73 \\
12.92 \\
16.90 \\
11.21 \\
13.99 \\
13.05 \\
10.58 \\
12.03 \\
15.21 \\
16.02\end{array}$ & $\begin{array}{l}1.90 \\
1.26 \\
3.25 \\
2.09 \\
2.29 \\
2.78 \\
1.99 \\
2.20 \\
2.56 \\
2.29 \\
2.02 \\
2.15\end{array}$ & $\begin{array}{l}12.03 \\
15.84 \\
11.73 \\
12.98 \\
17.07 \\
11.41 \\
14.48 \\
12.47 \\
10.19 \\
12.63 \\
15.05 \\
15.78\end{array}$ & $\begin{array}{l}2.37 \\
1.15 \\
3.53 \\
2.32 \\
2.23 \\
3.38 \\
2.00 \\
2.38 \\
2.90 \\
2.51 \\
1.99 \\
2.48\end{array}$ \\
\hline
\end{tabular}

Inspection of Tables 1 and 2 shows that neither parents nor adolescents set significantly different ages for boys and girls. In fact almost all respondents set exactly the same ages for boys and girls for every question.

The data were further analysed by way of sex, age and family size for parents, and by way of sex, grade level and family size for adolescents.

With regard to parent data, it was found that fathers consistently set ages that were approximately five months higher than those set by mothers. Additionally the older parents tended to set higher ages than the younger parents. No family size effects were observed.
With regard to adolescent data, there were no sex or family size effects, but students in year 7 set ages that were approximately six months higher than those set by students in years 8 and 9 , which were essentially equal.

In order to make overall comparisons between parents' and adolescents' responses, an overall mean of the means for each question was computed. Given the lack of difference between ages set for boys and girls, the data for the two groups have been combined. These overall means are presented in Table 3. 
Table 3

Overall mean ages suggested by Parents and Adolescents by way of Area.

\begin{tabular}{lcccc}
\hline & North-Western & Eastern & Rural & Total \\
\hline Parents & 14.91 & 14.58 & 14.73 & 14.74 \\
Adolescents & 14.01 & 13.38 & 13.42 & 13.60 \\
Difference & 0.90 & 1.20 & 1.31 & 1.14 \\
& $(11$ Months $)$ & $(14$ Months $)$ & (16 Months) & (14 Months) \\
\hline
\end{tabular}

Inspection of Table 3 shows that similar patterns existed in the responses of parents and adolescents in that the working class families were the more conservative and set the highest ages, followed by the rural families and then the middle class families. As far as parent adolescent differences are concerned, however, the largest difference occurred with the rural families, followed by middle class and working class families in that order.

\section{ADDITIONAL STUDY}

In order to examine any differences resulting from ethnic background, a small replication of the above study was carried out in a secondary school with a high proportion of ethnic students. Comparisons were made between adolescents of Greek, Italian and Australian families. Families were considered to be of a particular ethnic origin if the parents were born and raised in that country. The questionnaires sent home to the ethnic families were translated into the appropriate language. Seventy families of each ethnic origin were randomly selected from the school population. The return rates were $40 \%, 44 \%$ and $44 \%$ for the Greek, Italian and Australian parents respectively, and $100 \%$ for all adolescent groups who completed the questionnaire (in English) during classes.

For the purposes of global cross-cultural comparisons, overall means of mean responses to each question were calculated for each group and are presented in Table 4.

Table 4

Mean responses of Parents and Adolescents by way of Ethnic Groups.

\begin{tabular}{lccc}
\hline & Greek & Italian & Australian \\
\hline Parents & 16.4 & 15.9 & 15.1 \\
Adolescents & 14.6 & 14.6 & 14.2 \\
Difference & 1.8 & 1.3 & .9 \\
& $(22$ months $)$ & (16 months) & (11 months) \\
\hline
\end{tabular}

Inspection of Table 4 shows that Greek and Italian parents are more conservative than their Australian counterparts. Although the Greek and Italian adolescents are also more conservative than their Australian counterparts, parent adolescent differences are greater in these families.

\section{DISCUSSION}

It is not possible in this paper to give full discussion to all of the issues raised by inspection of the data in the results tables. The comments made here will be restricted to the use that might be made of the data by practitioners who work with families experiencing serious parent adolescent conflict.

Psychologists working with families in turmoil are likely to continue to be asked what either their own or other peoples' views are regarding the appropriate ages to grant adolescents autonomy to engage in behaviours like those mentioned in the questionnaire. The following points would seem likely to be worth considering in framing a response:
1. Notwithstanding the various group differences reported in the results, the standard deviations reported in Tables 1 and 2 indicate that there is considerable variation of opinion within each group of respondents. Several questions produced responses with standard deviations in excess of three years. Clearly practitioners must be aware of this extensive variation of opinion within groups, and accept that for any given issue (e.g., alcohol consumption) the successfully negotiated solution may vary considerably from family to family.

2. The means reported in Tables 1 and 2 should be of value to practitioners in informing family members what most other people think regarding the issues in question. The offering of these mean figures should be accompanied, however, by some information on the variation of opinion. 
3. The data given in Table 3 should give practitioners some idea of the extent of likely differences in opinion between parents and adolescents, and hence be useful in advising family members regarding ambit claims in the negotiation process. Given that successful negotiation usually involves compromise, negotiation of an issue in say a rural family will require a compromise of about eight months by both parent and adolescent if they are "to meet in the middle".

4. The data in Table 4 suggest that successful negotiation is likely to be more difficult in Greek and Italian families since the need for compromise is greater. The same data, however, should be useful in advising members of these families regarding ambit claims.

\section{REFERENCES}

Besalel, V.A., \& Azrin, N.H. (1981). The reduction of parent-youth problems by reciprocity counselling. Behaviour Research and Therapy, 19, 287-301.

Blechman, E.A. (1977). Objectives and procedures believed necessary for the success of a contractual approach to family intervention. Behaviour Therapy, 8 , 275-277.

Grinder, R.E. (1973). Adolescence. New York: John Wiley.

Lefrancois, G.R. (1976). Adolescents. Belmont, California: Wadsworth.

Raue, J., \& Spence, S. (1985). Group versus individual applications of reciprocity training for parent-youth conflict. Behaviour Research and Therapy, 23, 177-186.

Robin, A.L. (1980). Parent-adolescent conflict: A skilltraining approach. In D.P. Rathjen \& J.P. Foreyt (Eds.), Social competence: Interventions for children and parents. Elinsford, N.Y.: Pergamon. 